\title{
Hybrid Electrically Pumped Evanescent Si/InGaAsP Lasers
}

\author{
Xiankai Sun, Avi Zadok, Michael J. Shearn, Kenneth A. Diest, Alireza Ghaffari, Harry A. Atwater, \\ Axel Scherer, and Amnon Yariv \\ Department of Applied Physics, MC 128-95, California Institute of Technology, Pasadena, CA 91125, USA \\ xksun@caltech.edu avizadok@caltech.edu
}

\begin{abstract}
Hybrid Si/InGaAsP Fabry-Perot evanescent lasers are fabricated via wafer bonding. Compared with previous similar devices, the current threshold density, turn-on voltage, output power and slope efficiency are all improved. Images show modal confinement to Silicon.
\end{abstract}

(C)2009 Optical Society of America

OCIS codes: (250.5960) Semiconductor lasers; (250.5300) Photonic integrated circuits.

\section{Introduction}

Chip-level, monolithic integration of laser sources together with high speed, Si integrated circuits has constituted a "holy grail" for research and development for over 30 years. Unfortunately, the indirect bandgap of Si renders it a poor converter of electricity to light, and the epitaxial growth of III-V layers of sufficient quality and thickness has been proven to be a major obstacle. Recent years witnessed a major reawakening of this interest, pursued primarily to support high rate communication among multiple processors [1]. Numerous avenues have been followed towards obtaining Si-integrated lasers, including optically pumped Raman amplification [2], rare-earth doping [3] and nanocrystalline Si structures [4]. One successful approach is based on low temperature bonding of InGaAlAs material on top of a pre-patterned Si-on-insulator (SOI) wafer [5-7]. The geometry of the bonded structure is designed to support a joint optical mode, whose profile overlaps both materials. Using this underlying technology, the InGaAlAs layers, which include multiple quantum wells (MQWs), could be patterned post-bonding to produce Fabry-Perot (FP) [5], racetrack [6] and distributed feedback (DFB) lasers [7], the output of which is largely confined to a Si waveguide. A similar approach was implemented in Si-coupled microdisc lasers [8], although their output power was restricted to tens of $\mu \mathrm{W}$.

One of the key challenges facing the large scale integration of hybrid Si/III-V active devices is the extent of heat generated in the laser [9]. Heat conduction away from the active region is hampered by the poor thermal conductivity of the lower cladding $\mathrm{SiO}_{2}$ layer. It is therefore of upmost importance to reduce both the lasing threshold current and the voltage of the devices, and increase their efficiency. In this work, we demonstrate hybrid $\mathrm{Si} / \mathrm{III}-\mathrm{V}$, evanescent FP lasers based on a different III-V material system, that of InGaAsP layers. The threshold current density and the threshold voltage of the fabricated devices at $15^{\circ} \mathrm{C}$ are $1.25 \mathrm{kA} / \mathrm{cm}^{2}$ and $1.3 \mathrm{~V}$ respectively, representing a 30-40\% improvement over those of the previously reported hybrid evanescent FP lasers [5]. The turnon voltage of the lasers is as low as $0.8 \mathrm{~V}$. At the same time, the output power and differential slope efficiency of the devices are improved as well, reaching $12.5 \mathrm{~mW}$ per facet and $8.4 \%$ per facet, respectively. The results are preliminary, and may be further improved considerably with the implementation of longitudinally varying modal confinement control [10]. High resolution near field images of the output facet, taken with an infra-red camera, show that the lasing mode is predominantly confined to the $\mathrm{Si}$ waveguide. We also examine the dependence of the laser performance on the width of the Si waveguide. A minimum width of about $900 \mathrm{~nm}$ is required to achieve continuous wave $(\mathrm{CW})$ lasing operation for the laser structure under study. This observation may be interpreted in terms of modal confinement.

\section{Design and fabrication}

The hybrid laser structure consisted of a SOI and InGaAsP wafers bonded together. The thicknesses of the buried $\mathrm{SiO}_{2}$ layer and the undoped $\mathrm{Si}$ device layer were $2.0 \mu \mathrm{m}$ and $900 \mathrm{~nm}$, respectively. A waveguide was defined in the $\mathrm{Si}$ device layer using electron beam lithography and subsequent $\mathrm{SF}_{6} / \mathrm{C}_{4} \mathrm{~F}_{8}$ reactive ion etching. The $\mathrm{Si}$ waveguide width was varied between $800 \mathrm{~nm}$ and $1.3 \mu \mathrm{m}$. The Si to the two sides of the waveguide was entirely etched, down to the $\mathrm{SiO}_{2}$ layer. The details of the key structural layers of the InGaAsP wafer are provided in table 1 below. The wafer design guidelines closely follow those of [5], albeit in a different material system.

The bonding procedure began with solvent and hydrofluoric acid cleaning of both surfaces. A $10 \mathrm{~nm}$ thick oxide layer was grown on top of the patterned SOI wafer, to enhance the bonding strength. The oxide layer was thermally grown at a high temperature of $800^{\circ} \mathrm{C}$, however the thermal growth will be replaced in future work by low temperature $\left(<350^{\circ} \mathrm{C}\right)$ plasma enhanced chemical vapor deposition of $\mathrm{SiO}_{2}$. The surfaces of the two wafers were 


\section{OThN1.pdf}

then activated through exposure to oxygen plasma, and bonded together under a pressure of $0.1 \mathrm{MPa}$ at $300^{\circ} \mathrm{C}$ for 1 hour. Low temperature, plasma assisted bonding was shown to be a powerful tool for integrating dissimilar material systems [5, 11]. Following the bonding, the InP substrate was removed by hydrochloric acid wet etching. An $80 \mu \mathrm{m}$ wide mesa structure was formed in the InGaAsP layers, centered above the Si waveguide, through photolithography and subsequent three-phase wet etching of the various layers down to the n-InP contact layer. Metal contacts were deposited for the $\mathrm{p}$-side on the $\mathrm{p}$-InGaAs layer at the top of the mesa, and for the $\mathrm{n}$-side on the exposed n-InP layer to the two sides of the mesa. The flow of current in the device was laterally confined to a $5 \mu \mathrm{m}$ wide channel, by means of proton implantation on its two sides [5]. Prior to the measurements, the SOI wafer substrate was lapped down to $50 \mu \mathrm{m}$ thickness, and individual device bars were cleaved and annealed at a temperature of $410^{\circ} \mathrm{C}$ for $10 \mathrm{~s}$. Figure 1 shows scanning electron microscope (SEM) images of the device cross-section, as well as a top view optical microscope image.

Table 1: InGaAsP wafer layers

\section{Layer}

p-side contact layer

Upper cladding layer

Separate confinement layers

Quantum wells (1\% compressive strain)

Barriers ( $0.3 \%$ tensile strain)

Separate confinement layers

$\mathrm{n}$-side contact layer

Super-lattice

Bonding layer

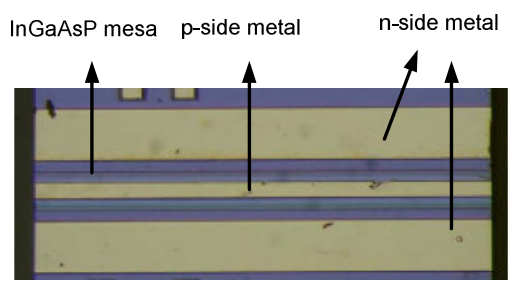

\begin{tabular}{|c|c|c|c|}
\hline Material & Thickness [nm] & Bandgap $[\mathrm{eV}]$ & Doping $\left[\mathrm{cm}^{-3}\right]$ \\
\hline $\mathrm{p}-\mathrm{In}_{0.53} \mathrm{Ga}_{0.47} \mathrm{As}$ & 200 & 0.77 & $\mathrm{p}>10^{19}$ \\
\hline p-InP & 1500 & 1.34 & $\mathrm{p}=10^{18} \rightarrow 5 \cdot 10^{17}$ \\
\hline InGaAsP & 40 & 1.08 & \\
\hline InGaAsP & 40 & 0.99 & \\
\hline InGaAsP (x5) & 7 & 0.83 & \\
\hline InGaAsP (x4) & 10 & 0.99 & undoped \\
\hline InGaAsP & 40 & 0.99 & \\
\hline InGaAsP & 40 & 1.08 & \\
\hline n-InP & 110 & 1.34 & $\mathrm{n}=10^{18}$ \\
\hline$n-\operatorname{InGaAsP}(\mathrm{x} 2)$ & 7.5 & 1.13 & $\mathrm{n}=10^{18}$ \\
\hline $\mathrm{n}-\mathrm{InP}(\mathrm{x} 2)$ & 7.5 & 1.34 & $\mathrm{n}=10^{18}$ \\
\hline n-InP & 10 & 1.34 & $\mathrm{n}=10^{18}$ \\
\hline
\end{tabular}

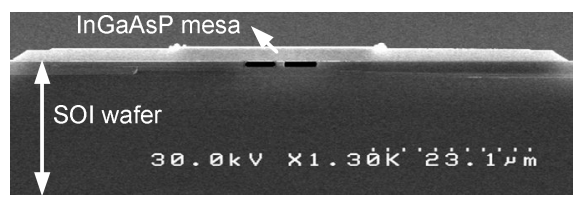

Fig. 1. Left: top view of a fabricated device. Center: SEM overview of cross-section of the device. Right: SEM close-up view of the device cross section in the $\mathrm{Si}$ waveguide region. Approximate ion implanted regions are superimposed on the image for illustration purposes.

\section{Measurement results}

Figure 2 (upper left) shows an L-I-V curve of a $960 \mu \mathrm{m}$ long device, mounted on a thermo-electric cooler at $15^{\circ} \mathrm{C}$. The device turn-on voltage was $0.8 \mathrm{~V}$, and the lasing threshold voltage was $1.3 \mathrm{~V}$. The threshold current was $60 \mathrm{~mA}$, corresponding to a threshold current density of $1.25 \mathrm{kA} / \mathrm{cm}^{2}$. The maximum power output from a single facet was $12.5 \mathrm{~mW}$, and the differential slope efficiency for a single facet was $8.4 \%$. The series resistance of the laser was $8 \Omega$. With the exception of the resistance, all the above parameters represent $30-40 \%$ improvement upon previously reported results for FP hybrid lasers [5]. Despite the conceptual similarities, many differences exist between the two devices (material system, number of quantum wells, various fabrication details), and further work is necessary to fully investigate the differences in performance. Nonetheless, the potential for obtaining improved devices has been demonstrated. Figure 2 (upper right) shows the laser spectrum. The central wavelength is $1490 \mathrm{~nm}$.

A high resolution near field image of the output laser beam is shown in Fig. 2 (bottom), superimposed on a scaled SEM cross section image of the device. The light spot appearing in cyan at the left-had sidewall of the device is attributed to a small current leakage obtained in the particular laser. While such current leakage is undesired, it is used here for the vertical registration of the InGaAsP mesa. The image provides a striking illustration to the confinement of the lasing mode in the Si waveguide $[5,10]$. To the best of our knowledge, such images have not been reported to date. 


\section{OThN1.pdf}
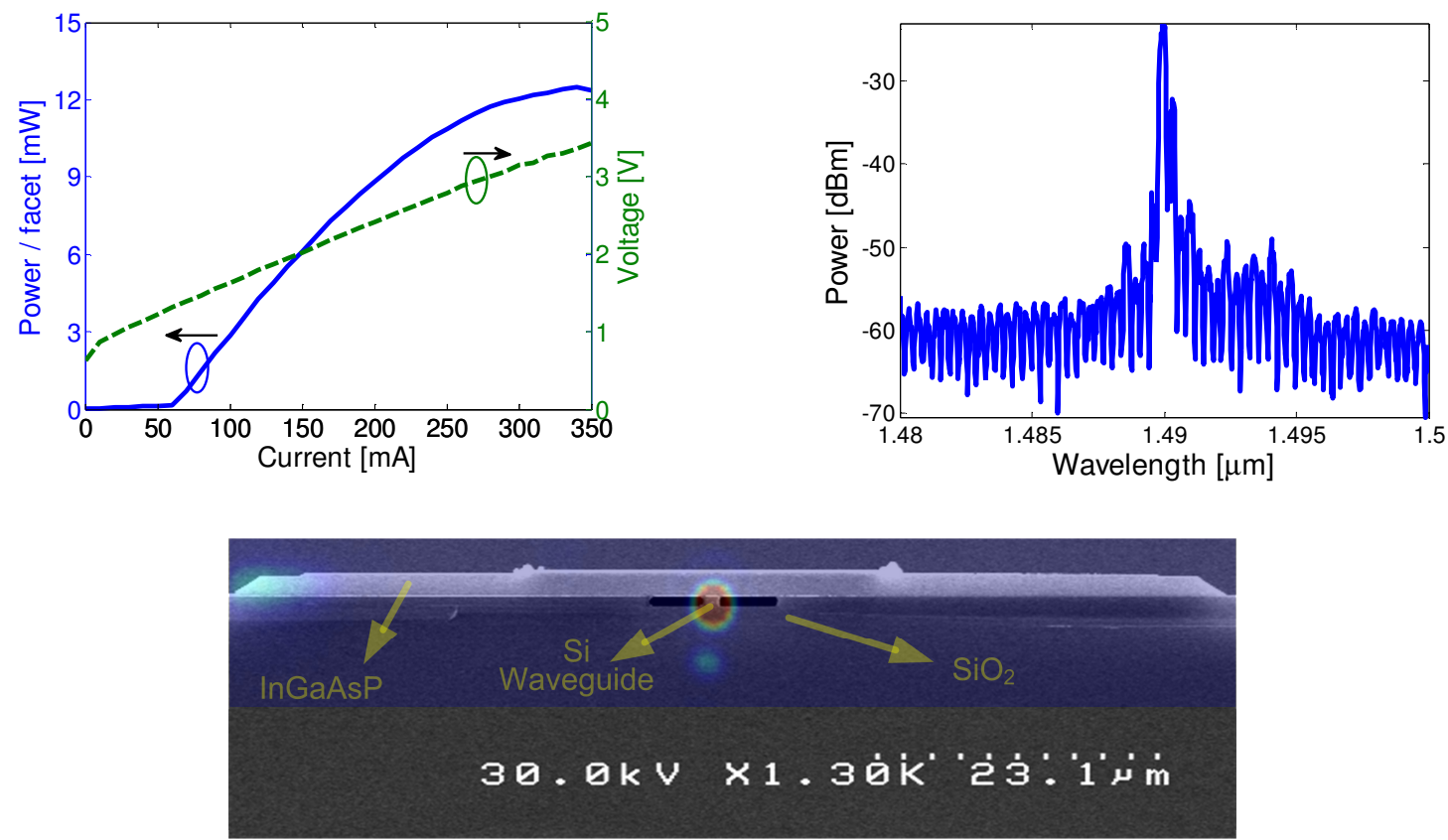

Fig. 2. Upper left: L-I-V curve of the laser under $\mathrm{CW}$ operation at $15^{\circ} \mathrm{C}$. Upper right: laser spectrum, linear scale. Bottom: near field image of the lasing mode, superimposed upon a scaled SEM cross section view of the device.

Finally, the performance of devices having different $\mathrm{Si}$ waveguide width $W$ was compared. While CW lasing was achieved in all 15 devices with $W \geq 900 \mathrm{~nm}$, it could not be obtained in any of 5 devices built with $W=800 \mathrm{~nm}$. We attribute this sharp transition in performance to the modal confinement. With a narrow Si waveguide the hybrid mode is largely confined to the III-V material [10]. However, since the cleaved facets fracture along the $\mathrm{Si}$ crystalline plane and there is no precise angular alignment between the wafers at the bonding stage, the feedback provided to the mode in these conditions is very poor. Increasing $W$ results in greater confinement of the mode to the $\mathrm{Si}$ waveguide, leading to stronger feedback. Future work will make use of these observations to control the optical confinement along the cavity. Such control is expected to provide significant further improvement in device performance [10].

\section{Acknowledgements}

This work has been supported by DARPA, under contract no. N66001-07-1-2058. The authors wish to thank the Kavli Nano-Institute, Caltech, for supporting the fabrication work. A. Z. thanks the support of post-doctoral fellowships from the Center for Physics in Information, Caltech, and the Rothschild foundation, Israel. M. S. thanks the support of the NSF Graduate Research Fellowship program.

\section{References}

[1] B. Jalali, "Teaching silicon new tricks," Nature Photon. 1, 193-195 (2007).

[2] O. Boyraz and B. Jalali, "Demonstration of a silicon Raman laser," Opt. Express 12, 5269-5273 (2004).

[3] S. Lombardo, "A room temperature luminescence from $\mathrm{Er}^{3+}$ implanted semi-insulating polycrystalline silicon," Appl. Phys. Lett. 63, 19421944 (1993).

[4] L. Pavesi, L. Dal Negro, C. Mazzoleni, G. Franzo, and F. Priolo, “Optical gain in silicon nanocrystals,” Nature 408, 440-444 (2000).

[5] A. W. Fang, H. Park, O. Cohen, R. Jones, M. J. Paniccia, and J. E. Bowers, "Electrically pumped hybrid AlGaInAs-silicon evanescent lasers," Opt. Express 14, 9203-9210, (2006).

[6] A. W. Fang, R. Jones, H. Park, O. Cohen, O. Raday, M. J. Paniccia, and J. E. Bowers, "Integrated AlGaInAs-silicon evanescent racetrack laser and photodetector," Opt. Express 15, 2315-2322, (2007).

[7] A. W. Fang, E. Lively, Y.-H. Kuo, D. Liang, and J. E. Bowers, "A distributed feedback silicon evanescent laser," Opt. Express 16, 4413$4419,(2008)$

[8] J. Van Campenhout, P. Rojo Romero, P. Regreny, C, Seassal, D. Van Thouhrout, S. Verstyuft, L. Di Cioccio, J.-M. Fedeli, C. Lagahe, and R. Baets, "Electrically pumped InP based microdisk lasers integrated with a nanophotonic silicon-on-insulator waveguide circuit," Opt. Express 15, 6744-6749, (2007).

[9] M. N. Sysak, H. Park, A. W. Fang, J. E. Bowers, R. Jones, O. Cohen, O. Radai, and M. J. Paniccia, "Experimental and theoretical thermal analysis of a hybrid silicon evanescent laser," Opt. Express 15, 15041-15046 (2007).

[10] X. K. Sun and A. Yariv, "Engineering supermode silicon/III-V hybrid waveguides for laser oscillations", J. Opt. Soc. Am. B 25, 923-926, (2008).

[11] D. Pasquariello and K. Hjort, "Plasma-assisted InP-to-Si low temperature wafer bonding," IEEE J. Sel. Top. Quantum Elect. 8, 118-131, (2002) 